\title{
An analytical basis for the generation of NPP emergency operation limiting pressure-temperature curves
}

\author{
Kutsenko O., Kadenko I., Kharytonov O., Sakhno N. \\ Taras Shevchenko National University of Kyiv \\ 64/13, Volodymyrska Street, 01601, Kyiv, Ukraine
}

(Received 1 July 2016)

\begin{abstract}
An analytical solution of the non-stationary axisymmetric thermoelasticity problem of the pressurized thermal shock event for unbounded two-layered elastic cylinder has been proposed. The physical and mechanical properties of the cylinder materials were assumed to be temperature independent. The thermal boundary conditions correspond to the stepwise medium temperature drop at the inner cylinder surface. The outer cylinder surface has been considered as heat-insulated. Given solution has been applied to the development of analytical basis for the generation of nuclear power plant emergency operation limiting pressure-temperature curves. The comparison of the results of analytical approach with the results of finite-element analysis performed for real, temperature-dependent material properties has been carried out. The accuracy of the analytical results is shown to be sufficient for the application of the given analytical approach for the generation of the limiting curves.
\end{abstract}

Keywords: nonstationary thermoelasticity, two-layered elastic cylinder, thermal shock, pressurized vessel, limiting $p-T$ curves, numerical examples.

2000 MSC: 74B05, 74B99

UDC: $539.3,621.039$

\section{Introduction}

The Emergency Operating Instructions (EOIs) define the activities of nuclear power plant (NPP) operator in the case of emergency. The procedures of EOI are divided into two categories. One category deals with specific events and their diagnosis; for these events, guidance is provided to recover the plant in an optimal manner. The second category makes no attempt to diagnose an event. It concentrates only on protecting the barriers against release of radiation. This second category of guidelines is called Function Restoration Guidelines (FRGs). The FUNCTIONS referred to in the title are those activities or conditions which must be satisfied to assure that the physical barriers to radiation release are maintained. Three barriers are considered: the fuel matrix and cladding, the reactor coolant system boundary and the containment building. To support the barriers to radiation release, a set of Critical Safety Functions is defined. For the assurance of the Reactor Coolant System (RCS) safety the Critical Safety Function "Integrity" is generated. The intent in monitoring the "Integrity" Critical Safety Function is to define symptoms that indicate a challenge to RCS integrity and to prioritize operator actions required to address this challenge. The first concern is transients that result in rapid and severe RCS cool-down coincident with a high or increasing primary system pressure that could lead to challenging vessel integrity (i.e., pressurized thermal shock (PTS)). The other concern is transients that occur while the RCS is relatively cold and a rapid pressure increase occurs (i.e., cold overpressure). The plant process parameters to be used in monitoring the "Integrity" Critical Safety Function are RCS pressure and RCS cold leg temperature. RCS pressure is an indication of the pressure in the downcomer region and cold leg temperature is the indication of downcomer fluid temperature. Limits to these RCS parameters are defined by Operational Limit Pressure-Temperature $(p-T)$ Curves 
for which typical example is presented in Fig. 1. The Operational Limit Curves divide the $T p$ plane into four regions identified with RED, ORANGE, YELLOW, and GREEN colors. Depending on the regions, the appropriate operator actions will be provided by the guidelines.

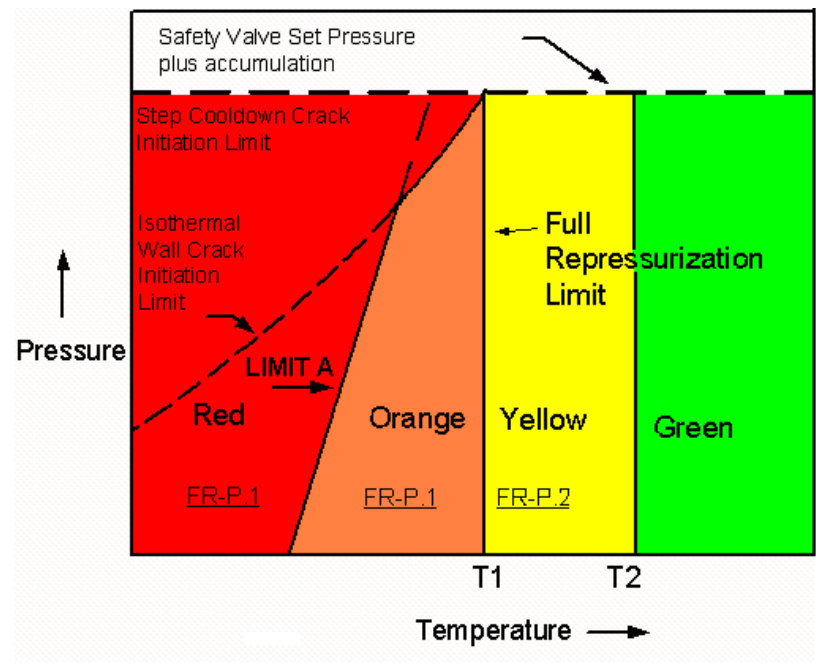

Fig. 1. Typical Operational Limits Curves for Integrity.

Above Limit curves are developed based on brittle fracture mechanics analysis which is commonly realized using Finite Element solution of the correspondent thermoelasticity problem. However, Finite Element calculation requires essential computational burden. Besides, validated codes and models must be used for such calculations. One of the most effective ways to reduce the computational burden, necessary for Limit $p-T$ curves generation, is the development of appropriate analytical approach. In addition, the analytical solution gives possibility to validate new Finite Element codes and models. An analytical approach to Limit $p-T$ curves generation is presented in the given paper.

\section{Model scenarios for limit $p-T$ curves development}

The problems, concerned with PTS analysis are divided into two categories. The first category includes the problems of the plant-life extension. For that category, the resistance of the Reactor Pressure Vessel (RPV) against fast fracture is assessed for the real PTS scenarios that can take place in the case of emergency. In that problems the exact simulation of the coolant mixing in the downcomer and the cold plumes influence analysis are of primary importance.

The problems from the second category deal with the EOI Operational Limit Curves generation. As the accident diagnostics is not required and only symptoms of the accident are taken into account, the conservative generalized model scenarios must be considered for Limit curves generation. The typical generalized model of PTS scenario is uniform step cool-down. In accordance with such scenario, the coolant temperature falls immediately from the normal operation temperature to the selected limiting values. For the RPV region the most conservative value is the hydraulic tanks water temperature of ECCS. At the same time, the primary circuit pressure does not lower and equals to the normal operating pressure value. Conservative value of the heat transfer coefficient should be applied. Such a scenario has a maximum available conservatism from the point of view of cool-down rate. From the other hand, using the comparative analysis [1] it was concluded that the temperature stresses due to uniform cooling down (the entire inner surface of RPV is cooled) are more dangerous than the stresses due to cold plumes (the part of the inner surface of RPV is cooled). Thus, the scenarios with the cold plumes lead to less severe thermal loading conditions than the uniform cool-down scenario.

\section{Thermoelasticity problem}

For the linear problem it is a possibility to carry out all the types of analysis (the heat conduction, structural and fracture mechanics analysis) independently. So, at each time point of PTS transient at first we can define the temperature fields, then the fields of stresses and then perform the brittle fracture analysis based on the stress intensity factor (SIF) calculation. The fields of temperature and stresses can be obtained from the solution of nonstationary thermoelasticity problem. This problem can be set for a two-layered hollow cylinder with an infinite length that represents a model of a RPV beltline zone. For the linear case, the thermoelasticity problem can be divided into two independent 
parts: the nonstationary problem of temperature field determination and the quasi-static problem of stress field determination. The solution of the last problem must be obtained at each time point of the transient.

\subsection{Heat conduction problem}

For the scenario of uniform cool-down, the temperature field is axisymmetric. The inner radius of the RPV is much more than the RPV wall thickness. Therefore, the axisymmetric problem of heat conduction in two-layered cylindrical wall can be considered as a problem of heat conduction in twolayered rod with unit cross-section area and heat-insulated lateral surface (Fig. 2). The length of the first part (cladding) is denoted as $h_{1}$ and the length of the second part (base metal) as $h_{2}$.

The convectional boundary conditions are imposed at the left end of the rod while the right end and the lateral surface are thermal insulated. It is supposed that the initial temperature of the rod is constant and equals to zero. At the initial time point of the transient, the temperature of the environment at the left end changes step-wise from zero

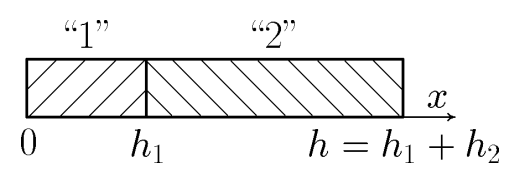

Fig. 2. Heat conduction problem geometry. to the value $T_{0}$. So, the corresponding heat conduction problem can be formulated as follows:

$$
\begin{gathered}
\frac{\partial T_{1}}{\partial t}=a_{1}^{2} \frac{\partial^{2} T_{1}}{\partial x^{2}}, \quad t>0, \quad 0<x<h_{1}, \quad \frac{\partial T_{2}}{\partial t}=a_{2}^{2} \frac{\partial^{2} T_{2}}{\partial x^{2}}, \quad t>0, \quad h_{1}<x<h, \\
\left.T_{1}\right|_{t=0}=0,\left.\quad T_{2}\right|_{t=0}=0,\left.\quad\left(T_{1}-\frac{\lambda_{1}}{H} \frac{\partial T_{1}}{\partial x}\right)\right|_{x=0}=T_{0},\left.\quad \frac{\partial T_{2}}{\partial x}\right|_{x=h}=0, \\
\left.T_{1}\right|_{x=h_{1}}=\left.T_{2}\right|_{x=h_{1}},\left.\quad \lambda_{1} \frac{\partial T_{1}}{\partial x}\right|_{x=h_{1}}=\left.\lambda_{2} \frac{\partial T_{2}}{\partial x}\right|_{x=h_{1}} .
\end{gathered}
$$

The following designations are used in (1)-(3): $T_{1}(x, t), 0<x<h_{1}$ is the temperature in the cladding, $T_{2}(x, t), h_{1}<x<h$ is the temperature in base metal, $h=h_{1}+h_{2}, a_{k}^{2}=\lambda_{k} /\left(\rho_{k} c_{k}\right), k=1,2$, where $\lambda_{k}, \rho_{k}, c_{k}$ are heat conductivities, densities, and specific heats of the rod parts materials, respectively; $H$ is the heat transfer coefficient. The conditions (3) are applied to assure the continuity of the temperature field and heat flux at the interface cross-section of the rod.

The solution of the problem (1)-(3) can be obtained using Laplace transformation

$$
\tilde{T}_{k}(x, s)=\int_{0}^{\infty} T_{k}(x, t) e^{-s t} d t, \quad k=1,2,
$$

where $s$ is complex parameter of the transformation.

The representations $\tilde{T}_{k}(x, s)$ are given as the solution to the following problem:

$$
\begin{gathered}
\frac{\partial^{2} \tilde{T}_{k}}{\partial x^{2}}-\frac{s}{a_{k}^{2}} \tilde{T}_{k}=0, \quad k=1,2, \\
\left.\left(\tilde{T}_{1}-\frac{\lambda_{1}}{H} \frac{\partial \tilde{T}_{1}}{\partial x}\right)\right|_{x=0}=\frac{T_{0}}{s},\left.\quad \frac{\partial \tilde{T}_{2}}{\partial x}\right|_{x=h}=0,\left.\quad \tilde{T}_{1}\right|_{x=h_{1}}=\left.\tilde{T}_{2}\right|_{x=h_{1}},\left.\quad \lambda_{1} \frac{\partial \tilde{T}_{1}}{\partial x}\right|_{x=h_{1}}=\left.\lambda_{2} \frac{\partial \tilde{T}_{2}}{\partial x}\right|_{x=h_{1}} .
\end{gathered}
$$

This is the boundary problem for two ordinary differential equations with constant coefficients, therefore it can be easily reduced to linear algebraic system. Finally the solution of the problem can be written in the form

$$
\tilde{T}_{k}(x, s)=\frac{T_{0}}{s} \frac{\tilde{\Delta}_{k}(s, x)}{\tilde{\Delta}_{0}(s)}, \quad k=1,2
$$


where

$$
\begin{aligned}
\tilde{\Delta}_{0}(s) & =\cosh \xi \cosh \beta \xi+\alpha \sinh \xi \sinh \beta \xi+\gamma \xi[\sinh \xi \cosh \beta \xi+\alpha \cosh \xi \sinh \beta \xi], \\
\tilde{\Delta}_{1}(s, x) & =\cosh \beta \xi \cosh \left(1-x / h_{1}\right) \xi+\alpha \sinh \beta \xi \sinh \left(1-x / h_{1}\right) \xi \\
\tilde{\Delta}_{2}(s, x) & =\cosh \left(1-\left(x-h_{1}\right) / h_{2}\right) \beta \xi, \quad \xi=\frac{h_{1}}{a_{1}} \sqrt{s}, \quad \alpha=\frac{a_{1} \lambda_{2}}{a_{2} \lambda_{1}}, \quad \beta=\frac{h_{2} a_{1}}{h_{1} a_{2}}, \quad \gamma=\frac{\lambda_{1}}{h_{1} H} .
\end{aligned}
$$

To define the temperature fields, the inverse Laplace transformation must be performed in accordance with the rule

$$
T_{k}(x, t)=\frac{1}{2 \pi i} \int_{m-i \infty}^{m+i \infty} \tilde{T}_{k}(x, s) e^{s t} d s, \quad k=1,2, \quad m>0 .
$$

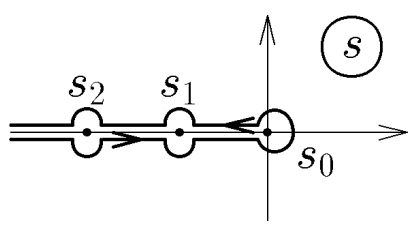

Fig. 3. Path of integration for the inverse Laplace transformation.

Note, that the function $\sqrt{s}$ is two-valued. Its branches can be extracted on the plane with the cut that connects the infinitely far point with the origin. However, the representations $\tilde{T}_{k}(x, s)$ are single-valued functions. Really, if the mentioned cut is drawn along the negative part of the real axis, the branches of the function $\sqrt{s}$ take at the faces of the cut the pure imaginary values with the opposite signs. Since function $\cosh (x)$ is even, the representations (4) are single-valued. Therefore, the singular points of representations are poles that are located on the negative part of the real axis with initial pole $s_{0}=0$. So, the path of the integration in (5) can be deformed in such a way that is presented in Fig. 3 and the originals can be calculated as sums of residues of integrands in (5). In fact, the above procedure expresses the application of the second expansion theorem of operational calculus.

Taking into account that $\sqrt{s}$ takes pure imaginary values on the path of integration, it is reasonable to introduce the designation $\mu=i \xi=i \frac{h_{1}}{a_{1}} \sqrt{s}$. Then the zeros of the correspondent denominators can be expressed as $s_{n}=-\left(\frac{a_{1}}{h_{1}} \mu_{n}\right)^{2}$. The equation for the definition of these zeros can be written in the form

$$
\cos \mu_{n} \cos \beta \mu_{n}-\alpha \sin \mu_{n} \sin \beta \mu_{n}-\gamma \mu_{n}\left(\sin \mu_{n} \cos \beta \mu_{n}+\alpha \cos \mu_{n} \sin \beta \mu_{n}\right)=0, \quad n=1,2,3, \ldots
$$

Calculating the residuals of the integrands in (5), one can obtain the solution of the heat conduction problem (1)-(3) in the following form

$$
T_{k}(x, t)=T_{0}\left[1-2 \sum_{n=1}^{\infty} \frac{\Delta_{k}\left(\mu_{n}, x\right)}{\mu_{n} \Delta_{0}\left(\mu_{n}\right)} e^{-\left(\frac{a_{1} \mu_{n}}{h_{1}}\right)^{2} t}\right], \quad k=1,2,
$$

where

$$
\begin{aligned}
\Delta_{0}\left(\mu_{n}\right) & =\delta_{1} \sin \mu_{n} \cos \beta \mu_{n}+\delta_{2} \cos \mu_{n} \sin \beta \mu_{n}+\delta_{3} \cos \mu_{n} \cos \beta \mu_{n}+\delta_{4} \sin \mu_{n} \sin \beta \mu_{n}, \\
\Delta_{1}\left(\mu_{n}, x\right) & =\cos \beta \mu_{n} \cos \left(1-x / h_{1}\right) \mu_{n}-\alpha \sin \beta \mu_{n} \sin \left(1-x / h_{1}\right) \mu_{n}, \\
\Delta_{2}\left(\mu_{n}, x\right) & =\cos \left(1-\left(x-h_{1}\right) / h_{2}\right) \mu_{n}, \\
\delta_{1} & =1+\alpha \beta+\gamma, \quad \delta_{2}=\alpha+\beta+\alpha \gamma, \quad \delta_{3}=(1+\alpha \beta) \gamma \mu_{n}, \quad \delta_{4}=-(\alpha+\beta) \gamma \mu_{n},
\end{aligned}
$$

$\mu_{n}$ are the roots of the equation (6). 


\subsection{Quasi-static thermoelasticity problem}

As the inertia forces produced in the RPV wall due to temperature variation are negligible, it can be supposed that at certain time point $t$ thermal stresses are defined by the temperature field that realized at that time point. So, in the thermoelasticity problem the time variable can be considered as a parameter.

Consider an equilibrium state of two-layered cylinder (Fig. 4) with inner layer defined by the radial coordinate interval $a<r<b$ (corresponds to cladding) and outer layer $b<r<c$ corresponds to base metal of RPV wall. Let us denote the parameters of the first layer by the index "1" and of the second layer - by the index " 2 ". It is important that for the RPV wall materials Poisson coefficients are equal for the base metal and cladding. The only loading applied to the cylinder is thermal loading due to nonuniform temperature field $T(r, t), a<r<c, t>0$. At each time point the temperature field $T(r, t)$ in two-layered cylinder can be approximately presented by the expressions (6), (7), where following relationships must be used: $x=r-a, h_{1}=b-a, h_{2}=c-b$. The task is to determine the longitudinal $\sigma_{z}$ and circumferential $\sigma_{\vartheta}$ stresses, since they are of the main importance for the fracture analysis.

Let us consider at first the case of rigid fixing of the cylinder ends:

$$
\left.w_{k}\right|_{z=0}=\left.w_{k}\right|_{z=l}=0, \quad k=1,2,
$$

where $l$ is the cylinder length and $w$ is the longitudinal displacement. Taking into account the plane deformation condition $\varepsilon_{z k}=\frac{d w_{k}}{d z} \equiv 0$, it can be concluded that $w_{k} \equiv 0$.

As a problem is axisymmetric, the stresses that arises in both cylinder layers satisfy the equations

$$
\frac{d \sigma_{r k}}{d r}+\frac{\sigma_{r k}+\sigma_{\vartheta k}}{r}=0, \quad k=1,2,
$$

where $\sigma_{r k}$ are radial stresses and index $k=1,2$ corresponds to the number of a layer. The tangential stresses are absent due to equality of Poisson coefficients of the cylinder layers.

To obtain the governing equation from (8) one can apply Hooke's law with the hypothesis of the plane strain conditions. For the plane strain $\varepsilon_{z k}=0, k=1,2$ (where $\varepsilon_{z}$ is the longitudinal strain) and the longitudinal stresses $\hat{\sigma}_{z k}$ can be expressed through the circumferential and radial stresses using correspondent relation of Hooke's law:

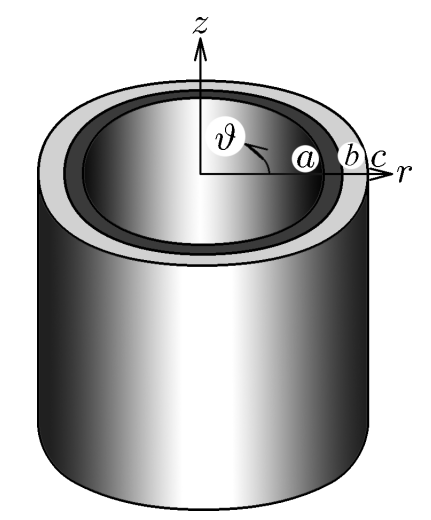

Fig. 4. Thermoelasticity problem geometry.

$$
\hat{\sigma}_{z k}=\nu\left(\sigma_{r k}+\sigma_{\vartheta k}\right)-\alpha_{k} E_{k} T, \quad k=1,2 .
$$

The other Hooke's law relations can be written in the form

$$
\begin{aligned}
& \varepsilon_{r k}-(1+\nu) \alpha_{k} T=\frac{1-\nu^{2}}{E_{k}}\left(\sigma_{r k}-\frac{\nu}{1-\nu} \sigma_{\vartheta k}\right), \\
& \varepsilon_{\vartheta k}-(1+\nu) \alpha_{k} T=\frac{1-\nu^{2}}{E_{k}}\left(\sigma_{\vartheta k}-\frac{\nu}{1-\nu} \sigma_{r k}\right), \quad k=1,2,
\end{aligned}
$$

where $\varepsilon_{r}$ and $\varepsilon_{\vartheta}$ are radial and circumferential strains, $E$ is Young modulus, $\nu$ is Poisson coefficient, $\alpha$ is thermal expansion coefficient.

For the axisymmetric problem the relations between strains and displacements may be expressed in a following manner:

$$
\varepsilon_{r k}=\frac{d u_{k}}{d r}, \quad \varepsilon_{\vartheta k}=\frac{u_{k}}{r}, \quad k=1,2,
$$

where $u$ is radial displacement. 
Substitution of the relations (11) into the equations (10) leads to the governing equation for the radial displacement

$$
\frac{d}{d r}\left(\frac{1}{r} \frac{d\left(r u_{k}\right)}{d r}\right)=\frac{1+\nu}{1-\nu} \alpha_{k} \frac{d T}{d r}, \quad k=1,2 .
$$

The general solution of the equation (12) can be written as

$$
u_{k}=\frac{1+\nu}{1-\nu} \alpha_{k} \frac{1}{r} \int_{r_{k}}^{r} \operatorname{Tr} d r+C_{2 k-1} r+\frac{C_{2 k}}{r}, \quad k=1,2, \quad r_{1}=a, \quad r_{2}=b .
$$

Expressions for circumferential and radial stresses can be obtained from the solution (13) using (11) and (10). They have the form

$$
\begin{aligned}
\sigma_{\vartheta k} & =\frac{\alpha_{k} E_{k}}{1-\nu} \frac{1}{r^{2}} \int_{r_{k}}^{r} \operatorname{Tr} d r-\frac{E_{k}}{1+\nu}\left[\alpha_{k} T+\left(\frac{C_{2 k-1}}{1-2 \nu}+\frac{C_{2 k}}{r^{2}}\right)\right], \\
\sigma_{r k} & =-\frac{\alpha_{k} E_{k}}{1-\nu} \frac{1}{r^{2}} \int_{r_{k}}^{r} \operatorname{Tr} d r+\frac{E_{k}}{1+\nu}\left(\frac{C_{2 k-1}}{1-2 \nu}-\frac{C_{2 k}}{r^{2}}\right), \quad k=1,2 .
\end{aligned}
$$

To obtain the well-defined final expressions for the stresses, one must define the arbitrary constants $C_{1}, C_{2}, C_{3}$ and $C_{4}$ from the boundary conditions. The boundary conditions are represented by the stress-free conditions on the lateral surface of the cylinder

$$
\left.\sigma_{r 1}\right|_{r=a}=\left.\sigma_{r 2}\right|_{r=c}=0,
$$

and the conditions of the continuity of the fields of stresses and displacements at the cladding-base metal interface

$$
\left.u_{1}\right|_{r=b}=\left.u_{2}\right|_{r=b},\left.\quad \sigma_{r 1}\right|_{r=b}=\left.\sigma_{r 2}\right|_{r=b} .
$$

The final expressions for the circumferential stresses have the following form:

$$
\begin{aligned}
& \sigma_{\vartheta 1}=\frac{\alpha_{1} E_{1}}{1-\nu} \frac{1}{r^{2}}\left[\frac{r^{2}+a^{2}}{b^{2}-a^{2}} \int_{a}^{b} T r d r+\int_{a}^{r} \operatorname{Tr} d r-T r^{2}\right]-\frac{r^{2}+a^{2}}{b^{2}-a^{2}} \frac{b^{2}}{r^{2}} q, \\
& \sigma_{\vartheta 2}=\frac{\alpha_{2} E_{2}}{1-\nu} \frac{1}{r^{2}}\left[\frac{r^{2}+b^{2}}{c^{2}-b^{2}} \int_{b}^{c} T r d r+\int_{b}^{r} T r d r-T r^{2}\right]+\frac{r^{2}+c^{2}}{c^{2}-b^{2}} \frac{b^{2}}{r^{2}} q,
\end{aligned}
$$

where

$$
q=\frac{\frac{2 \alpha_{1}}{b^{2}-a^{2}} \int_{a}^{b} \operatorname{Tr} d r-\frac{2 \alpha_{2}}{c^{2}-b^{2}} \int_{b}^{c} \operatorname{Tr} d r}{\frac{a^{2}+(1-2 \nu) b^{2}}{\left(b^{2}-a^{2}\right) E_{1}}+\frac{c^{2}+(1-2 \nu) b^{2}}{\left(c^{2}-b^{2}\right) E_{2}}} .
$$

After the definition of circumferential and radial stresses the longitudinal stresses can be determined from the expressions (9). Such an approach makes it possible to find the longitudinal stresses for the case of the rigid fixing of the ends of cylinder. These stresses can be used to obtain the longitudinal stresses in the case of free ends of cylinder. The difference between the longitudinal stresses in these two cases (rigid fixing and free ends of cylinder) is dealt with the stresses due to compressed longitudinal thermal deformation which is absent in the case of free ends. So, the stresses for the case of free ends are 
equal to the difference between the stresses for the case of rigid fixing and the stresses corresponding to uniform longitudinal deformation. In accordance with Saint-Venan, principle the error of the simulation of the real stresses by the combination of two above mentioned fields is essential only for the area close to the ends of cylinder.

The longitudinal stresses due to compressed thermal deformation have the form

$$
\sigma_{z 1}^{0}=E_{1} \varepsilon_{0}, \quad \sigma_{z 2}^{0}=E_{2} \varepsilon_{0},
$$

where $\varepsilon_{0}$ is averaged compressed thermal deformation of the cylinder. It can be defined from statically equivalent load condition

$$
\varepsilon_{0}\left[E_{1}\left(b^{2}-a^{2}\right)+E_{2}\left(c^{2}-b^{2}\right)\right]=2 \int_{a}^{b} \hat{\sigma}_{z 1} r d r+2 \int_{b}^{c} \hat{\sigma}_{z 2} r d r .
$$

Representing the longitudinal stresses for the case of free ends $\sigma_{z k}$ accordingly to the outlined procedure, one can obtain the following expressions:

$$
\begin{aligned}
& \sigma_{z 1}=\frac{\alpha_{1} E_{1}}{1-\nu}\left[\frac{2}{b^{2}-a^{2}} \int_{a}^{b} T r d r-T\right]-\frac{Q}{b^{2}-a^{2}}, \\
& \sigma_{z 2}=\frac{\alpha_{2} E_{2}}{1-\nu}\left[\frac{2}{c^{2}-b^{2}} \int_{b}^{c} T r d r-T\right]+\frac{Q}{c^{2}-b^{2}},
\end{aligned}
$$

where

$$
Q=q\left[2 \nu b^{2}+\frac{\frac{a^{2}+(1-2 \nu) b^{2}}{\left(b^{2}-a^{2}\right) E_{1}}+\frac{c^{2}+(1-2 \nu) b^{2}}{\left(c^{2}-b^{2}\right) E_{2}}}{\frac{1}{\left(b^{2}-a^{2}\right) E_{1}}+\frac{1}{\left(c^{2}-b^{2}\right) E_{2}}}\right] .
$$

The expressions (17) and (18) give the final solution of the thermoelasticity problem. That is quite enough, because only longitudinal and circumferential stresses must be taken into account during fracture mechanics analysis.

To analyze the fracture conditions, the stresses due to inner pressure must be added to the obtained thermal stresses. The expressions for the stresses due to inner pressure can be easily developed from the general solution (13), (14), (9) putting $T \equiv 0$ and changing the conditions (15) in the following manner:

$$
\left.\sigma_{r 1}\right|_{r=a}=-p,\left.\quad \sigma_{r 2}\right|_{r=c}=0 .
$$

The final form of these expressions is

$$
\begin{aligned}
\sigma_{\vartheta 1} & =\frac{p a^{2}-q b^{2}}{b^{2}-a^{2}}+\frac{(p-q) a^{2} b^{2}}{\left(b^{2}-a^{2}\right) r^{2}}, & \sigma_{\vartheta 2} & =\frac{q b^{2}}{c^{2}-b^{2}}\left(1+\frac{c^{2}}{r^{2}}\right), \\
\sigma_{z 1} & =2 \nu \frac{p a^{2}-q b^{2}}{b^{2}-a^{2}}+E_{1} Q, & \sigma_{z 2} & =2 \nu \frac{q b^{2}}{c^{2}-b^{2}}+E_{2} Q
\end{aligned}
$$

where

$$
q=\frac{\frac{2(1-\nu) a^{2}}{\left(b^{2}-a^{2}\right) E_{1}} p}{\frac{a^{2}+(1-2 \nu) b^{2}}{\left(b^{2}-a^{2}\right) E_{1}}+\frac{c^{2}+(1-2 \nu) b^{2}}{\left(c^{2}-b^{2}\right) E_{2}}}, \quad Q=\frac{(1-2 \nu) a^{2} p}{\left(b^{2}-a^{2}\right) E_{1}+\left(c^{2}-b^{2}\right) E_{2}} .
$$


Note, that there are misprints in the correspondent expressions presented in [2].

\section{Verification of the analytical approach}

The proposed approach is verified by the comparison with the results of traditional Finite-Element calculation. For that purpose, the model problem of step cool-down PTS scenario for VVER-1000 RPV wall beltline zone has been considered. It was supposed that at the initial time point the RPV wall temperature field is uniform and the value of temperature corresponds to the normal operation conditions $\left(290^{\circ} \mathrm{C}\right)$. At the initial time point, the coolant temperature is step-wise changed to the value $110^{\circ} \mathrm{C}$. The geometrical data of the beltline zone is provided by Table 1 .

Table 1. Geometrical data of VVER-1000 RPV beltline zone.

\begin{tabular}{|l|l|}
\hline Inner radius, $a$ & $2.068 \mathrm{~m}$ \\
\hline Thickness of cladding, $h_{1}$ & $0.007 \mathrm{~m}$ \\
\hline Thickness of base metal, $h$ & $0.1995 \mathrm{~m}$ \\
\hline
\end{tabular}

The averaged values of physical properties of base metal and cladding are given in Table 2 (averaging is used for the temperature range $20-300^{\circ} \mathrm{C}$ ).

Table 2. Averaged values of physical properties of base metal and cladding for VVER-1000 RPV [3].

\begin{tabular}{|l|c|c|c|c|c|c|}
\hline \multirow{2}{*}{ Layer } & $E$ & $\alpha$ & $\nu$ & $\lambda$ & $c$ & $\rho$ \\
\cline { 2 - 7 } & {$\left[10^{3} \mathrm{MPa}\right]$} & {$\left[10^{-6} 1 / \mathrm{K}\right]$} & & {$[\mathrm{W} / \mathrm{m} \cdot \mathrm{K}]$} & {$[\mathrm{J} / \mathrm{kg} \cdot \mathrm{K}]$} & {$\left[\mathrm{kg} / \mathrm{m}^{3}\right]$} \\
\hline Cladding & 153 & 17.5 & 0.3 & 13.5 & 520 & 7830 \\
\hline Base metal & 193 & 13.5 & 0.3 & 36 & 520 & 7780 \\
\hline
\end{tabular}

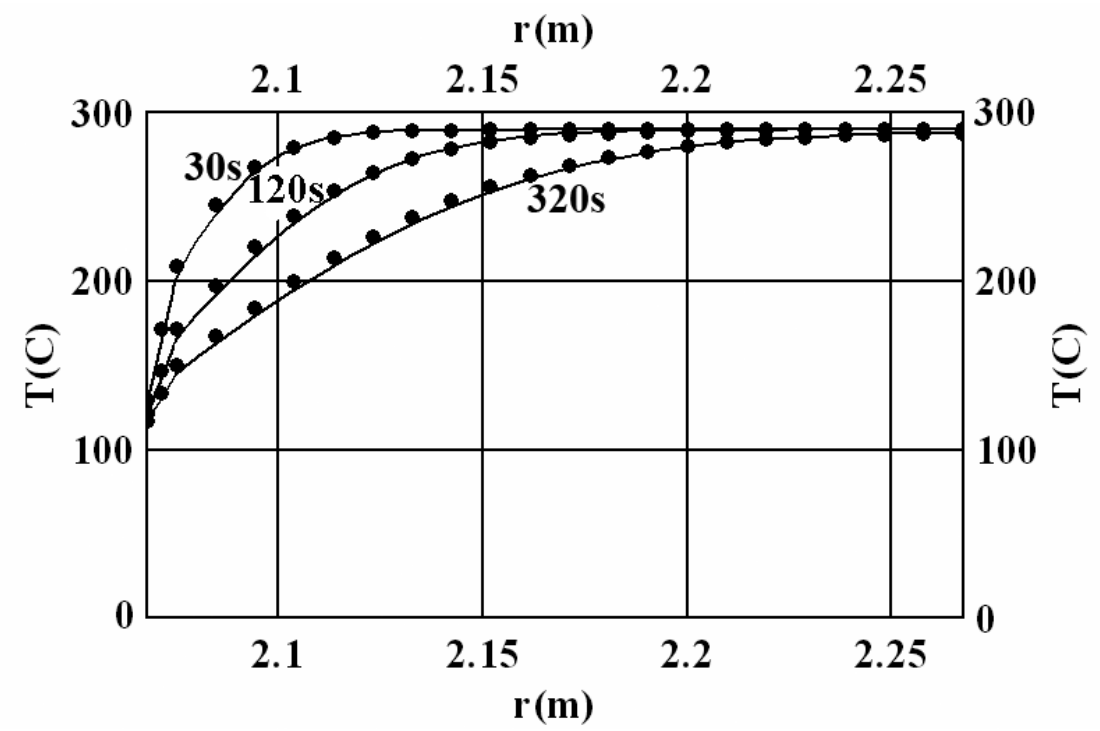

Fig. 5. Temperature distribution at different time points.

The distributions of temperature, circumferential and longitudinal stresses obtained using analytical and Finite-Element approaches are correspondently presented in Figs. 5-7. The temperature dependencies of physical properties [3] were used in numerical Finite-Element calculation, while the analytical approach is based on the averaged values (Table 2). The solid lines correspond to the 
analytical solution (7), (17)-(19), while the points correspond to the numerical Finite-Element solution. In these figures, three different curves correspond to the three time points of the PTS transient: $(t=30,120,320 \mathrm{~s})$. It can be concluded from Figs. $5-7$ that the differences between the analytical and numerical solutions are not essential (less than $5 \%$ ).

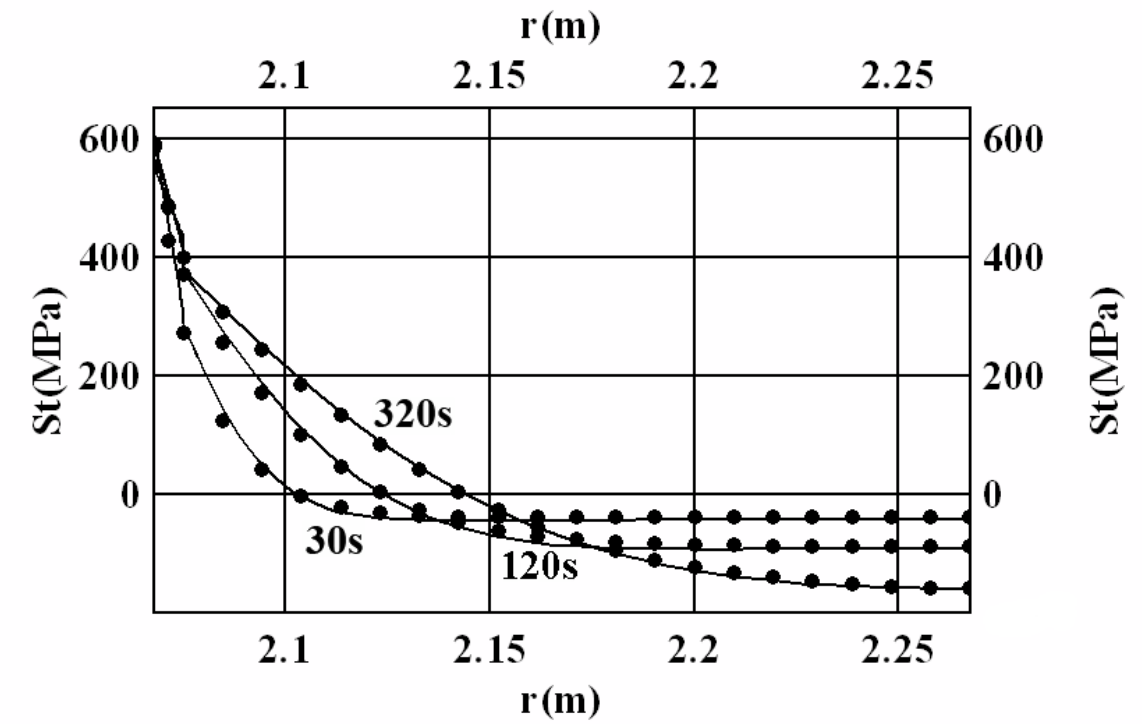

Fig. 6. Distribution of the circumferential stresses at different time points.

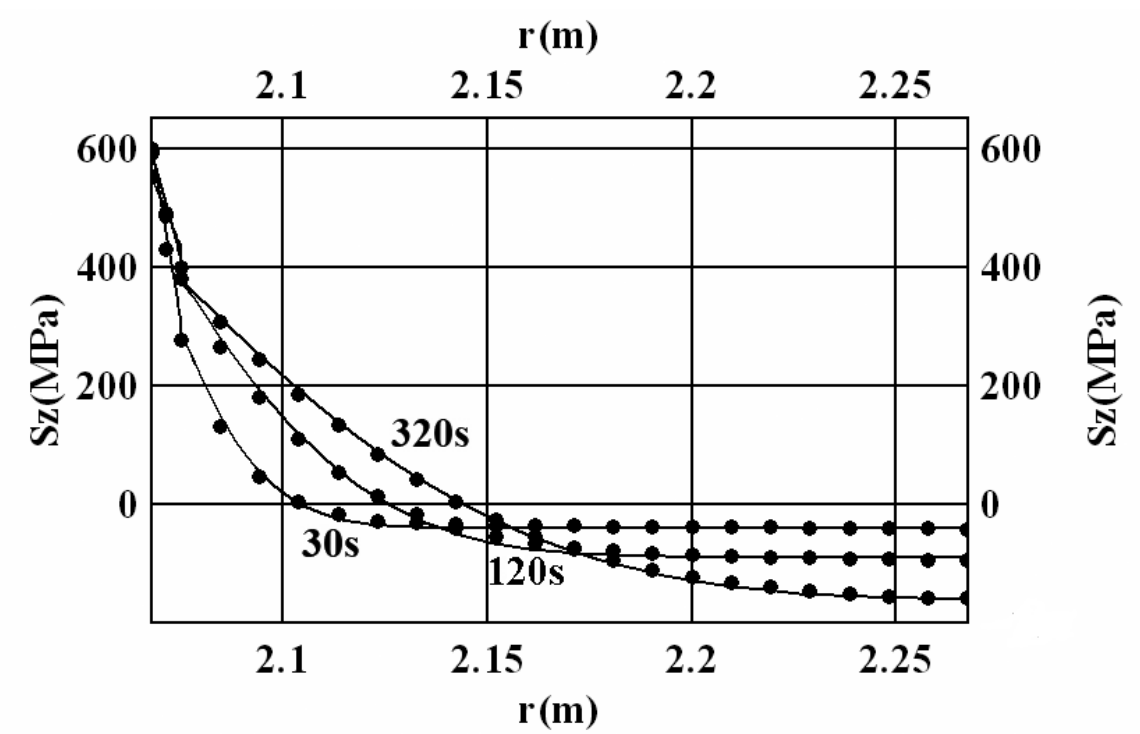

Fig. 7. Distribution of the longitudinal stresses at different time points.

The practical application of the proposed analytical approach is demonstrated by example of $p-T$ curve LIMIT A (Fig. 1) generation. LIMIT A is the curve on the $p-T$ plane, where $p$ is RCS pressure and $T$ is the cold leg temperature. This curve is generated in such a way that the resistance of RPV to brittle fracture is assured if the values of $p$ and $T$ are to the right from the curve. LIMIT A is an envelope of the two curves called "Step Cooldown Crack Initiation Limit" and "Isothermal Wall Crack Initiation Limit". PTS step cool-down model scenario has been considered to generate "Step Cooldown Crack Initiation Limit" curve. For such a scenario, the coolant temperature is step-wise falling from the value $290^{\circ} \mathrm{C}$ (normal operation cold leg temperature) to different values, correspondent to possible ECC water temperatures. The values to which temperature falls are put on the $T$ axis, while the values 
of pressure critical for correspondent transient are put on the $p$ axis. In the given example, the brittle fracture conditions have been analyzed for the surface circumferential and longitudinal semi-elliptical cracks with the depth equal to $1 / 4$ of wall thickness and aspect ratios 0.3 and 0.7 . For each time point of the transient, the critical pressure has been determined for all the cracks for a set of points at the crack front. The critical pressure has been determined from the formula

$$
K_{I}=p_{c r} \cdot K_{I}^{p}+K_{I}^{T}=\left[K_{I C}\right]
$$

where $K_{I}$ is a stress intensity factor, $K_{I}^{p}$ is a stress intensity factor per unit pressure, $K_{I}^{T}$ is a stress intensity factor due to thermal loading, $\left[K_{I C}\right]$ is a critical stress intensity factor.

The critical pressure put on the $p$ axis has been defined as a minimum from all the values calculated in the different time points of a transient.

For "Isothermal Wall Crack Initiation Limit" generation the series of constant RPV temperatures is considered. For each temperature value, the critical pressure is determined as a minimum from the pressures critical for all the cracks. The following formula is applied:

$$
K_{I}=p_{c r} \cdot K_{I}^{p}=\left[K_{I C}\right] .
$$

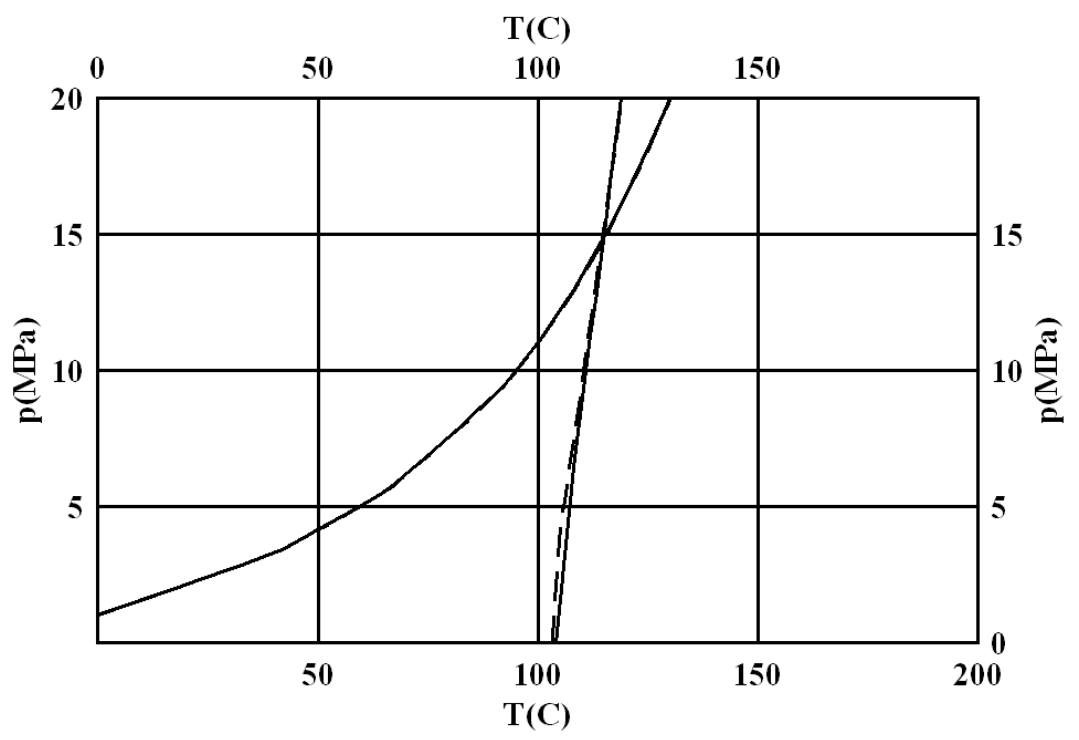

Fig. 8. LIMIT A curves.

The LIMIT A curves generated using analytical (solid line) and Finite Element (dashed line) approaches are presented in Fig. 8. The stress intensity factor values have been calculated using the same approach, based on superposition method. The following expressions were taken for $\left[K_{I C}\right][2,3]$ :

$\left[K_{I C}\right]_{3}(T)=\min \left\{26+36 \cdot \exp \left[0.02 \cdot\left(T-T_{k}\right)\right] ; 200 \mathrm{MPa} \cdot \sqrt{\mathrm{m}}\right\}$

- for "Step Cooldown Crack Initiation Limit" generation;

$\left[K_{I C}\right]_{1}(T)=\min \left\{13+18 \cdot \exp \left[0.02 \cdot\left(T-T_{k}\right)\right] ; 100 \mathrm{MPa} \cdot \sqrt{\mathrm{m}}\right\}$

- for "Isothermal Wall Crack Initiation Limit" generation.

From Fig. 8 it can be concluded that the difference in "Isothermal Wall Crack Initiation Limit" curves generated using analytical and Finite Element approaches is negligible. For "Step Cooldown Crack Initiation Limit" curve the maximal difference is less than $2{ }^{\circ} \mathrm{C}$. At the same time, the difference at ends of those curves is also negligible. 


\title{
5. Conclusions
}

The analytical approach to EOI limit $p-T$ curves generation has been proposed. The results obtained using given approach are compared with the results of Finite Element analysis. From the comparative analysis it can be concluded that the proposed analytical approach can be used for Operational Limit Pressure-Temperature $(p-T)$ Curves generation.

[1] Zrazhevskaya V.F., Zrazhevsky G. M.,Kutsenko O. G. Numerical solving of some non-stationary nonlinear problem of the thermoelasticity for the hollow cylinder Bulletin of University of Kyiv, Series: Physics \& Mathematics. 1, 53-59 (2007).

[2] PNAEG-G7-002-86 Rules and Regulations for Design and Stress Analysis for Components and Piping of Nuclear Installation Moscow, Energoatomizdat, PNAE G-7-002-86 (1989).

[3] IAEA-EBP-WWER-08 Guidelines on Pressurized Thermal Shock Analysis for WWER Nuclear Power Plants IAEA, Vienna (2006).

\section{Аналітичний підхід до побудови граничних кривих тиск-температура аварійних умов єксплуатації АЕС}

\author{
Куценко О. Г., Каденко І. М., Харитонов О. М., Сахно Н. В. \\ Київсъкий начіональний університет імені Тараса Шевченка \\ вул. Володимирсъка, 64/13, 01601, Київ, Україна
}

\begin{abstract}
Подано аналітичний розв'язок осесиметричної задачі нестаціонарної термопружності для події теплового удару нескінченного двошарового пружного циліндра. Фізикомеханічні властивості матеріалів циліндра вважалися незалежними від температури. Температурні граничні умови відповідають стрибкоподібній зміні температури середовища на внутрішній поверхні циліндра. Зовнішня поверхня циліндра вважається теплоізольованою. Цей розв'язок використано для розроблення аналітичного базису для побудови граничних кривих «температура-тиск», які застосовуються в аварійних інструкціях атомних електричних станцій. Проведене порівняння результатів застосування цього аналітичного підходу із результатами скінченно-елементного аналізу, отриманими в припущенні залежності властивостей матеріалів від температури. Результати порівняння свідчать про достатню практичну точність запропонованого методу.
\end{abstract}

Ключові слова: нестаціонарна термопружність, двошаровий пружній циліндр, термічний удар, резервуар під тиском, граничні $p-T$ криві, чисельний приклад.

2000 MSC: 74B05, 74B99

УдК: $539.3,621.039$ 